\title{
Anatomical Connections of the Visual Word Form Area
}

\author{
Florence Bouhali, ${ }^{1,2,4,10}$ Michel Thiebaut de Schotten, ${ }^{2,4,5,10}$ Philippe Pinel, ${ }^{7,8,9}$ Cyril Poupon, ${ }^{7,8,9}$ \\ Jean-François Mangin, ${ }^{7,8,9}$ Stanislas Dehaene, ${ }^{6,7,8,9}$ and Laurent Cohen ${ }^{1,2,3,4,10}$ \\ ${ }^{1}$ Inserm, U 1127, F-75013, Paris, France, ${ }^{2}$ Sorbonne Universités, UPMC Univ Paris 06, F-75013, Paris, France, ${ }^{3}$ AP-HP, Hôpital de la Pitié Salpêtrière, \\ Department of Neurology, F-75013, Paris, France, ${ }^{4}$ CNRS, F-75013, Paris, France, ${ }^{5}$ Natbrainlab, Department of Forensic and Neurodevelopmental Sciences, \\ Institute of Psychiatry, King's College London, London, United Kingdom, ${ }^{6}$ Collège de France, 75005 Paris, France, ${ }^{7}$ INSERM, Cognitive Neuroimaging Unit, \\ Gif sur Yvette 91191, France, ${ }^{8}$ Commissariat à l’Energie Atomique, Direction des Sciences du Vivant, I²BM, Neurospin center, Gif sur Yvette 91191, France, \\ ${ }^{9}$ Université Paris-Sud 11, 91405 Orsay, France, and ${ }^{10}$ Institut du Cerveau et de la Moelle épinière, ICM, F-75013, Paris, France
}

The visual word form area (VWFA), a region systematically involved in the identification of written words, occupies a reproducible location in the left occipitotemporal sulcus in expert readers of all cultures. Such a reproducible localization is paradoxical, given that reading is a recent invention that could not have influenced the genetic evolution of the cortex. Here, we test the hypothesis that the VWFA recycles a region of the ventral visual cortex that shows a high degree of anatomical connectivity to perisylvian language areas, thus providing an efficient circuit for both grapheme-phoneme conversion and lexical access. In two distinct experiments, using highresolution diffusion-weighted data from 75 human subjects, we show that (1) the VWFA, compared with the fusiform face area, shows higher connectivity to left-hemispheric perisylvian superior temporal, anterior temporal and inferior frontal areas; (2) on a posteriorto-anterior axis, its localization within the left occipitotemporal sulcus maps onto a peak of connectivity with language areas, with slightly distinct subregions showing preferential projections to areas respectively involved in grapheme-phoneme conversion and lexical access. In agreement with functional data on the VWFA in blind subjects, the results suggest that connectivity to language areas, over and above visual factors, may be the primary determinant of VWFA localization.

Key words: diffusion imaging; language; reading; visual word form area; white matter

\section{Introduction}

The first step in word reading is the computation of an ordered string of abstract letters, invariant for location, case, and other irrelevant visual features (Dehaene and Cohen, 2011). Studies of patients with pure alexia (Dejerine, 1892; Cohen et al., 2003; Pflugshaupt et al., 2009), and functional brain imaging (Nobre et al., 1994; Jobard et al., 2003; Glezer and Riesenhuber, 2013) have put to light a region in the left ventral occipitotemporal cortex (the visual word form area; VWFA), which is thought to carry out this computation (Cohen et al., 2000). The VWFA then broadcasts orthographic information to language areas involved in central aspects of reading, including stored lexical information (the "deep" reading route), and grapheme-phoneme conversion (the "surface" reading route; Jobard et al., 2003; Price, 2012).

Received Nov. 22, 2013; revised Aug. 26, 2014; accepted Sept. 3, 2014.

Author contributions: M.T.d.S., S.D., and L.C. designed research; F.B., P.P., C.P., J.-F.M., and L.C. performed research; F.B., M.T.d.S., P.P., C.P., J.-F.M., and L.C. analyzed data; F.B., M.T.d.S., S.D., and L.C. wrote the paper.

This work was supported by the program "Investissements d'avenir" ANR-10-IAIHU-06. The "Archi Database Part $1^{\prime \prime}$ is the property of the CEA I ${ }^{2}$ BM NeuroSpin centre and was designed under the supervision of C.P. and J.-F.M., and was funded by the Federative Research Institute 49, by the HIPPIP Grant and the European CONNECT project (http://www.brain-connect.eu). Acquisitions were performed by the scientists involved in the Multiscale Brain Architecture research program of NeuroSpin and by the staff of the BioMedical Laboratory of NeuroSpin (headed by Dr Lucie Hertz-Pannier), under the ethical approval CPP100002/CPP100022 (principal investigator Dr Denis Le Bihan). Access to the database can be requested from: cyril.poupon@cea.fr.

The authors declare no competing financial interests.

Correspondence should be addressed to Laurent Cohen, Service de Neurologie 1, Pavillon Paul-Castaigne, Hôpital de la Salpêtrière, 47 Bd de l'Hôpital, 75651 PARIS cedex 13, France. E-mail: laurentcohen2@gmail.com.

DOI:10.1523/JNEUROSCI.4918-13.2014

Copyright $\odot 2014$ the authors $\quad 0270-6474 / 14 / 3415402-13 \$ 15.00 / 0$
The VWFA is located lateral to the middle section of the fusiform gyrus, with remarkable reproducibility across subjects, even across a variety of script types (Cohen et al., 2000; Dehaene et al., 2002; Jobard et al., 2003; Bolger et al., 2005). To account for such consistent localization of the VWFA, two nonexclusive kinds of arguments have been put forward. First, this region may possess a priori perceptual biases that make it particularly suitable for reading, including preference for foveal versus peripheral stimuli (Hasson et al., 2002), analytical versus configural processing (Ventura et al., 2013), sensitivity to line junctions (Szwed et al., 2011), or perceptual invariance (Lerner et al., 2001). Second, this region lies anatomically close to the left perisylvian areas devoted to the processing of spoken language, and may therefore provide direct connections from visual to language areas. Supporting this latter view, the hemispheric lateralization of the VWFA is strongly correlated with the lateralization for spoken language (Cai et al., 2008, 2010; Pinel and Dehaene, 2010). Tracking the connections of the VWFA, Yeatman et al. (2013) identified fibers passing through the inferior longitudinal fasciculus (ILF), inferior fronto-occipital fasciculus (IFOF), and vertical occipital fasciculus of Wernicke (VOF). In addition, Epelbaum et al. (2008) found projections of the VWFA through the arcuate fasciculus (AF), presumably reaching superior temporal regions.

In the present study, using diffusion and functional imaging, we investigate the hypothesis that the location of the VWFA is tightly dependent on its anatomical connectivity to the language system. This hypothesis predicts that the location of the VWFA is 
characterized, on both lateral-to-medial and posterior-toanterior axes, by a particular "signature" of high anatomical connectivity to left-hemispheric perisylvian language areas. This idea generates two specific predictions, each assessed through a dedicated experiment. First, we predict that overall the VWFA should be more connected to language areas than a functionally distinct but anatomically contiguous area devoted to face processing (the fusiform face area; FFA). Second, considering that the VWFA is not functionally homogeneous along its posterior-to-anterior extent, we predict that its pattern of connection differs across the length of the occipitotemporal sulcus, reflecting the involvement of successive regions in visual, grapho-phonological, or lexical aspects of reading.

\section{Materials and Methods}

\section{Participants}

Seventy-nine French subjects gave written informed consent to participate in the "Archi Database Part 1" project (Neurospin, CEA, Saclay, France). All participants indicated French as their first language, had normal or corrected-to-normal visual acuity, and had no history of neurological, learning, or reading disorders.

Four subjects were excluded because of defects in fMRI acquisition (one subject) or handedness as assessed with the Edinburgh handedness inventory (Oldfield, 1971; three left-handed subjects), because lefthanded subjects are more likely to display atypical lateralization of both language networks and the VWFA (Cai et al., 2008; Van der Haegen et al., 2012). The current study was thus based on a database of 75 subjects ( 46 males/29 females, mean age 24 years, range 19-50, SD 5.3).

\section{Functional and anatomical MRI}

Stimulation paradigms. To isolate the VWFA, we contrasted activations by visual words minus checkerboards. To this end, we used a subpart of a functional localizer experiment whose details can be found in Pinel et al. (2007). For the word condition, we pooled (1) trials on which subjects simply had to covertly read short sentences (10 trials), and (2) trials on which sentences instructed subjects to press three times a left or right button ( 5 trials each). Visual sentences were broken down into four successive screens $(250 \mathrm{~ms}$ ) separated by $100 \mathrm{~ms}$ blank intervals. Each screen comprised one to three words, resulting on average in $1.3 \mathrm{~s}$ of trial duration per sentence. The baseline condition consisted in passively viewing flashing horizontal (10 trials) or vertical (10 trials) checkerboards. One checkerboard trial consisted in eight alternating black/white checkerboards, each displayed for $200 \mathrm{~ms}$.

To isolate the FFA, we used a subpart of the experimental conditions included in another short protocol designed to investigate social cognition, contrasting activations by faces minus scrambled images. In the face condition, subjects had to judge the gender or the trustworthiness of a human character according to his/her face. Before the trial, a sentence shortly displayed in the center of the video screen $(1200 \mathrm{~ms})$ reminded the task to be done ("face of a man or of a woman?" or "trustworthy or untrustworthy?"). Stimuli consisted in a series of 32 black and white images of standardized faces with direct gaze and neutral expressions, originally extracted from the Karolinska database (Lundqvist et al., 1998). In the control task, subjects had to decide whether a scrambled image of a face was straight or slightly tilted (preceded by the question "straight or tilted image?").

Both protocols were programmed using E-Prime software and organized as fast event-related paradigms: trials were intermixed in a random order, identical across subjects. Twenty percent of blank trials were added to the trial sequence, during which subjects saw a white fixation cross in the center of the screen.

Acquisition parameters. We used a 3-tesla MRI (Siemens Trio TIM) with a 12-channel head coil, and a gradient-echo planar imaging sequence sensitive to brain oxygen level-dependent contrast (40 contiguous axial slices, acquired using ascending interleaved sequence, $3 \mathrm{~mm}$ thickness; $\mathrm{TR}=2400 \mathrm{~ms}$; flip angle $=90^{\circ}, \mathrm{TE}=30 \mathrm{~ms}$, in-plane resolution $=3 \times 3 \mathrm{~mm}$, matrix $=64 \times 64$ ). For each acquisition, the first four volumes were discarded to reach equilibrium. T1-weighted images were also acquired for anatomical localization.

Data processing. Data were preprocessed using SPM8 software as follows: slice timing, motion correction, normalization to the MNI template (resampled voxel size $=3 \times 3 \times 3 \mathrm{~mm})$, and smoothing $(5 \mathrm{~mm}$ FWHM). Each voxel time series was fitted with a linear combination of functions derived by convolving a standard hemodynamic response function with the time series of the stimulus categories, plus their temporal derivatives. Individual contrast images were computed for the two contrasts of interest, then smoothed ( $5 \mathrm{~mm}$ FWHM), and eventually entered in a second level random effect group analysis.

We used functional and anatomical data to create two special types of images for use in Experiments 1 and 2 (Fig. 1B).

First, we created a group-level mask of reading-related left occipitotemporal activations. To this end, group level activations to the words minus checkerboards contrast were thresholded at a voxelwise $p<0.001$ uncorrected, and intersected with an anatomical mask of the left ventral stream. This yielded a left occipitotemporal volume extending from $y=$ -101 to $y=-37$, which was used subsequently for the definition of regions-of-interest (ROIs), as explained below. Using the same procedure, we also created a mask of face-related left occipitotemporal activations, based on the contrast of faces minus scrambled images, and used it subsequently for the definition of ROIs.

Second, we extracted for each individual brain, in its native space, the 1 -voxel-thick sheet of WM just beneath the cortical ribbon. To extract this sheet, native anatomical images were segmented into GM and WM using Morphologist/BrainVisa pipeline (http://brainvisa.info). Binarized GM volumes were then slightly inflated by smoothing them with a $2 \mathrm{~mm}$ FWHM isotropic Gaussian kernel, and applying a threshold of 0.2. Those GM volumes were then intersected with the WM volume, resulting in a 1-voxel-thick superficial sheet of white matter (Thiebaut de Schotten et al., 2014), which was used subsequently for the definition of ROIs.

\section{Diffusion-weighted imaging}

Acquisition and preprocessing. HARDI (high-angular resolution diffusion imaging) data were acquired in 60 directions with a $b$ value of 1500 $\mathrm{s} / \mathrm{mm} 2$ (voxel size of $1,7 \mathrm{~mm}^{3}$ ) using a twice refocusing spin-echo technique (Reese et al., 2003) compensating eddy currents to the first order. To improve the subjects' comfort, the acquisition was divided into three sessions of 19/20/21 diffusion directions, respectively, plus a null $b$ value volume at the beginning of each session, leading to a total of 3 null $b$ value data. The three subsets of directions were optimized such that (1) the directions of each set is almost uniformly distributed over the unit sphere, (2) the total set of directions is uniformly distributed, and (3) the three subsets have complementary directions (Dubois et al., 2006). All diffusion-weighted volumes were corrected for motion and matched to the first volume acquired at $b=0 \mathrm{~s} / \mathrm{mm}^{2}$. Geometrical distortions linked to susceptibility artifacts were corrected using a phase map acquisition. T1- and diffusion-weighted data of each subject were optimally aligned using a rigid $3 \mathrm{D}$ transform estimated by an automatic registration algorithm based on mutual information. Registration was performed between one diffusion-free T2-weighted image and the high-resolution T1-weighted image $(1 \times 1 \times 1.1 \mathrm{~mm}$ resolution).

Tractography. The diffusion orientation distribution function (ODF) was reconstructed in each voxel with an analytical solution of the q-ball model, using $\mathrm{SH}_{\max }=6$ and $\lambda_{\mathrm{LB}}=0.006$, allowing for a satisfactory resolution of fiber crossings (Descoteaux et al., 2007). Fiber tracts were reconstructed using the diffusion model estimation and a streamline deterministic tractography algorithm provided in Connectomist software. The tracts were calculated as the trajectories of particles with inertia, leading to regularized curvature (Perrin et al., 2005).

Streamline deterministic tractography was initiated from $27(3 \times 3 \times$ 3 ) seeds in each voxel of the propagation mask (with T1 resolution), in both retrograde and anterograde directions, according to the maximal direction of the underlying ODF. Retrograde and anterograde tracking were merged into one single tract. The tracking step was $0.4 \mathrm{~mm}$. Track- 


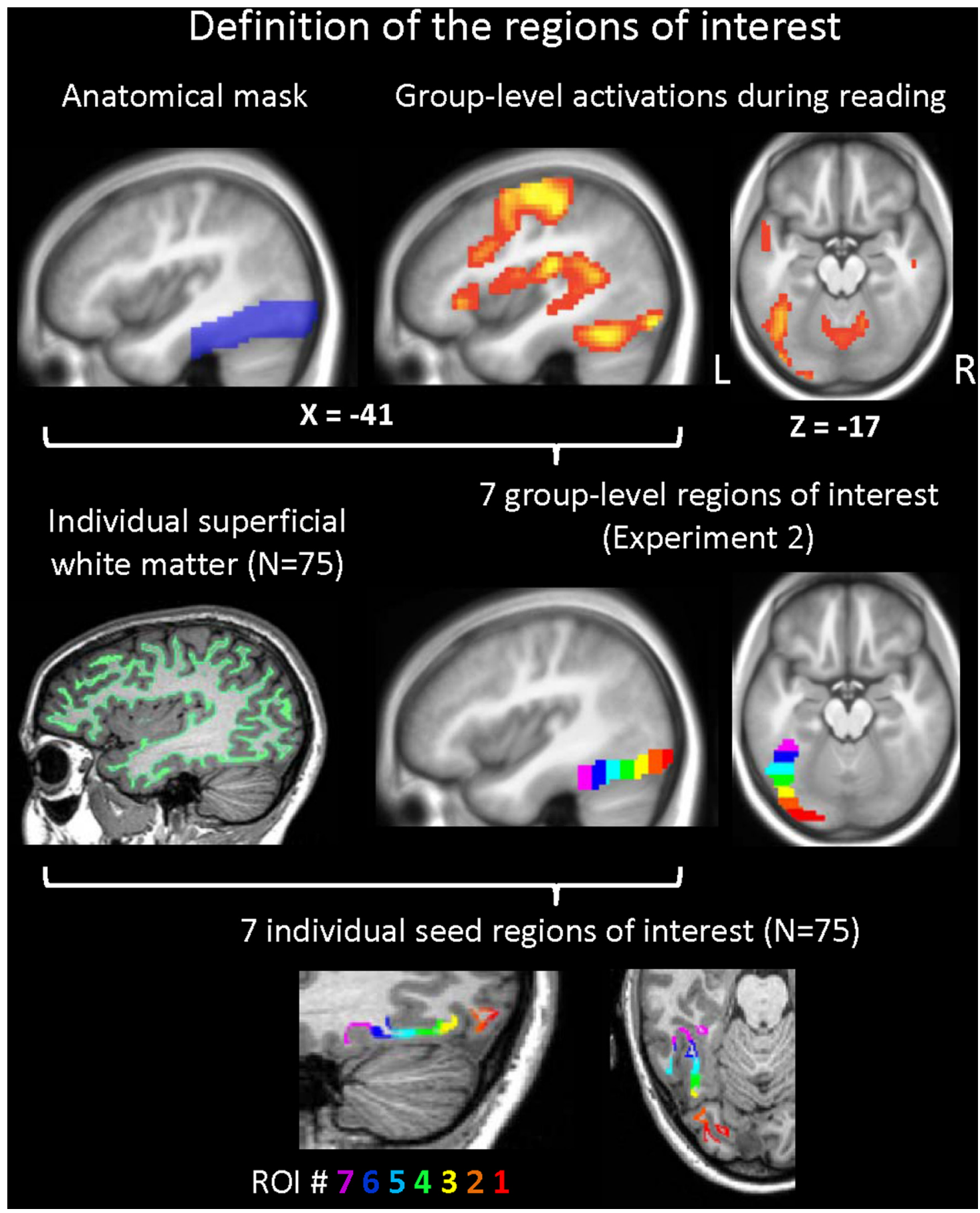

Figure 1. Definition of regions of interest. Method used for defining ROIs for tracking WM fibers, as illustrated in the case of Experiment 2. The VWF system was defined as the intersection of an anatomical mask with functional activations during reading, and was then divided into seven posterior to anterior ROIs, which were eventually transformed into individual ROls of superficial WM (see main text for details).

ing was stopped either when the particle exited the propagation mask, or when the angle between the two last moves exceeded $30^{\circ}$, or when the tract length exceeded $200 \mathrm{~mm}$

Tracking of fibers from ROIs. In Experiments 1 and 2, we defined ROIs that we used as seeds for tracking fibers. To this end, we selected all streamlines intersecting the given ROI on a minimal distance of $0.2 \mathrm{~mm}$. Individual connectivity maps, indicating in each voxel of the diffusion space the number of fibers passing through, were derived from those tractograms. Individual connectivity maps were then binarized and registered to an optimal FA template in MNI space drawn from the present dataset using Advance Normalization Tools (http://www.picsl.upenn.
edu/ANTS/). Affine and diffeomorphic deformations used for the registration were computed from individual FA maps to the obtained template (Avants et al., 2008; Klein et al., 2009). Similar methods are reported in Thiebaut de Schotten et al. (2011). Normalized connectivity maps were finally smoothed using a Gaussian kernel of $4 \mathrm{~mm}$ FWHM, and were used for statistical analyses as described below. 3D fusion images of connectivity or statistical maps with a mesh of the average gray-white interface from the MNI database were produced using the BrainVisa package (http://brainvisa.info). Except for the images of maximal projections in Figure 4, which use point-to-point fusion, each point of the mesh is labeled with the maximum value in a surrounding $5 \mathrm{~mm}$ sphere. 


\section{Results \\ Experiment 1: specificity of the connections of the VWF system}

In Experiment 1, we contrasted the connectivity of the VWFA and the FFA. Previous fiber-tracking studies indicate that the inferior occipitotemporal visual cortex, where the VWFA lies, is connected to the rest of the cortex by several fasciculi, including the ILF, the IFOF, the AF in its posterior temporoparietal and long temporofrontal segments, and the vertical occipital fasciculus projecting toward the angular gyrus and occipital lobe (Catani et al., 2005; Yeatman et al., 2012, 2013; Thiebaut de Schotten et al., 2014; see Figure 5). However, at present, only a global pattern of projections has been documented, and its specificity to the VWFA has not been demonstrated. Indeed, the above fasciculi are very large and seem as likely to link to neighboring regions with different functional specialization, such as the medially adjacent FFA. If our hypothesis is correct, however, the VWFA site should be singled-out by a preferential pattern of anatomical connectivity. We predicted that there should be systematically stronger projections of the VWFA to language areas, while the FFA should preferentially project to areas involved in social cognition, as previously proposed (Mahon and Caramazza, 2011; Saygin et al., 2011). To test this hypothesis, in a first study, we compared within subjects the pattern of anatomical connectivity of the VWFA and of the FFA.

\section{Definition of ROIs}

We took the reading-related and the face-related group-level activation masks (see Materials and Methods) and intersected them, thus deriving 3 ROIs: a reading-only or VWFA ROI, a more mesial face-only or FFA ROI, and in between the intersection of the two functional masks, which was activated during both reading and face perception. Posterior to $y=-70$, the two functional masks overlapped entirely, and the three ROIs were therefore truncated at $y=-70$ (Fig. 2A). We did not use directly those 3D ROIs as seeds, but wished to use ROIs restricted to the most superficial layer of white matter. This would allow us to select only fibers emerging from and projecting to the overlying gray matter and to exclude fibers passing through the neighboring white matter and not stopping at the target areas. To do so, we defined the 3 ROIs in the T1 native space of each participant by denormalizing group-level 3D ROIs. We intersected these denormalized ROIs with the subject's sheet of superficial white matter, and translated them from the anatomical to the individual diffusion space through a rigid transformation. Finally, we initiated the tracking following the methods described in Materials and Methods.

\section{Experiment 1 results}

Figure $2 B$ shows the respective connectivity of the VWFA and the FFA ROIs. Maps indicate the connectivity index, computed as the mean of normalized and smoothed individual connectivity maps, with a threshold of $50 \%$. Left-hemispheric projections extended roughly throughout the ventral half of the left hemisphere's surface, including the lateral and ventral occipital and temporal lobes, the temporal pole, the inferior and orbital frontal lobe. We found no projection to the right hemisphere above the $50 \%$ threshold. On visual inspection, the projections of the VWFA and FFA ROIs spanned approximately the same area, with suggestions of some local differences.

To assess those differences, we statistically compared the projections of the VWFA ROI and of the FFA ROI across the whole brain. To this end, we entered individual normalized smoothed connectivity maps in a nonparametric repeated-measures ANOVA using the permutation method, as implemented in FSL software (Nichols and Holmes, 2002). This analysis included one within-subject factor (the 3 ROIs), one regressor of noninterest (the individual volume of the ROI), and subjects were treated as a random factor. 5000 permutations were run and the thresholdfree cluster enhancement (TFCE) method was applied (Smith and Nichols, 2009). We report results significant at a threshold of 0.05 , familywise error (FWE) corrected, based on the TFCE statistic image. Within this model, we contrasted the projections of the VWFA ROI and of the FFA ROI minus the other two ROIs (Fig. 2C). This showed that the VWFA connected significantly more to most perisylvian language-related areas, including Broca's area and insula, the superior and lateral temporal lobe, and the posterior inferior parietal lobule. In contrast, the FFA connected more to the mesial occipital and temporal lobes, including the hippocampus, the lingual and parahippocampal gyri, and the amygdala, and to the posterolateral occipital lobe. To delineate the overlap of regions connected to the VWFA and to the FFA, we identified voxels connected to both ROIs with a connectivity index $>50 \%$, and moreover showing no statistical difference between their connectivity to the two ROIs. Those regions included the temporal pole, the lateral occipital cortex, the orbitofrontal cortex (Fig. 2D).

Finally, we checked whether anatomical connectivity differed across subjects as a function of individual functional activations. To this end, using the same statistical technique as before, we entered individual normalized smoothed connectivity maps of the VWFA ROI in a nonparametric ANOVA with two regressors: the individual mean value of the reading-related contrast within the VWFA mask as the factor-of-interest, and the individual volume of the ROI as a regressor of noninterest. This allowed us to look for regions where anatomical connectivity would be correlated to activation level. A parallel analysis was run on individual connectivity maps of the FFA using the faces-related activation level within the FFA as the factor of interest. Those two analyses yielded no significant correlation of distant anatomical connectivity with activation level.

\section{Experiment 1 summary}

We showed that, despite their close anatomical proximity, the VWFA and the FFA had significantly distinct patterns of anatomical connectivity. As predicted, the VWFA was more connected to perisylvian language areas, whereas the FFA was more connected to mesial visual and limbic structures.

\section{Experiment 2: posteroanterior connectivity of the VWF system}

Describing the VWFA as a small homogeneous patch of cortex surrounding a single activation peak would be naive phrenology. Actually, the ventral occipitotemporal region involved in reading, more aptly called VWF system, extends from posterior occipital cortex to the anterior fusiform gyrus (Szwed et al., 2011). The VWFA strictly speaking may be seen as the most wordspecific patch within this more extended system. Along this axis, the VWF system shows a functional gradient, with increasing invariance for position (Dehaene et al., 2004) and increasing sensitivity to high-level statistical properties of letter combinations (Vinckier et al., 2007) as moving more anterior. This view is supported by recent meta-analyses which both support the caudorostral model of reading specialization within the left ventral stream, by showing a more lexically oriented system the more rostral one goes (Cattinelli et al., 2013; Taylor et al., 2013). This is 
A

Definition of ROls

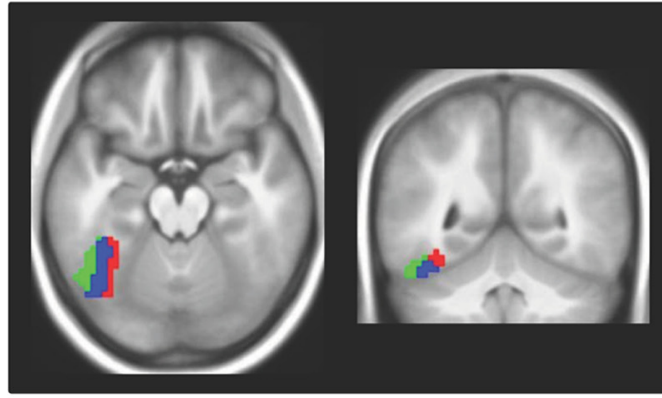

VWFA

- FFA

intersection

B

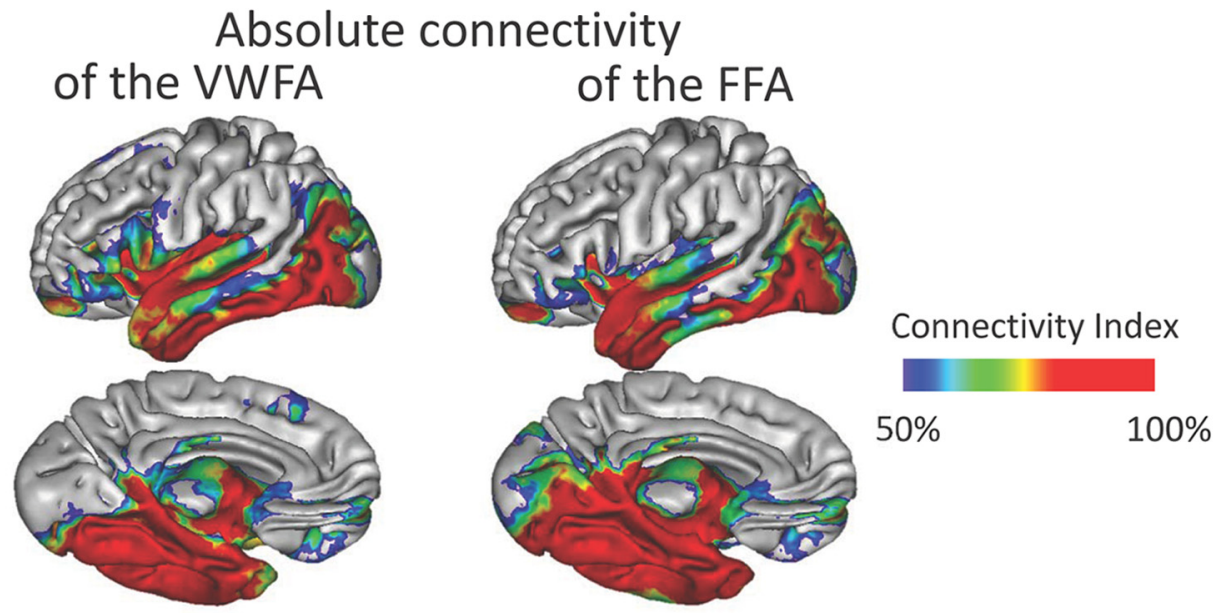

C Differential connectivity: t-test $(P<0.05)$

VWFA-others

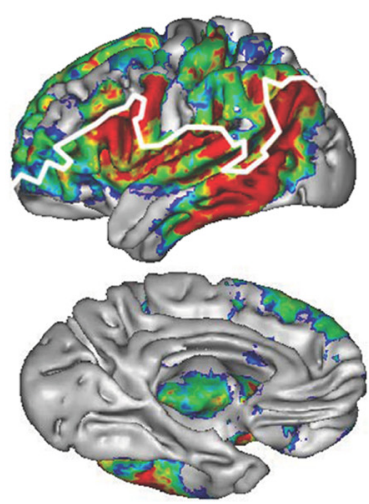

FFA-others

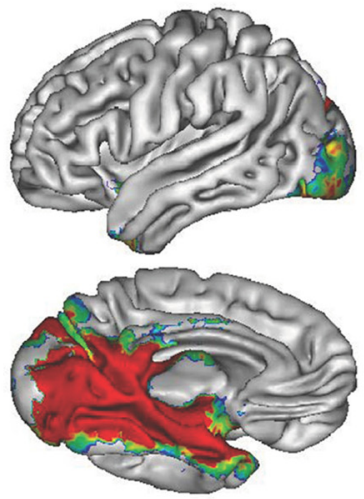

t value

1.87

D Shared connectivity of the VWFA and FFA
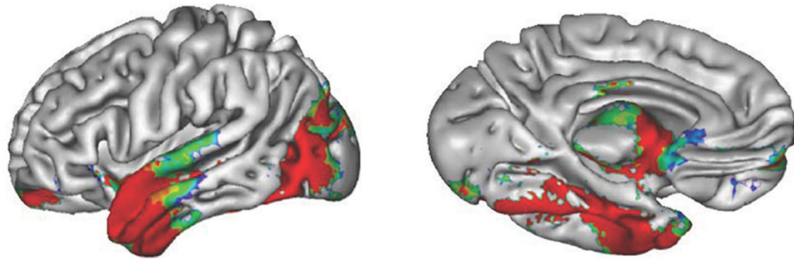

Connectivity Index

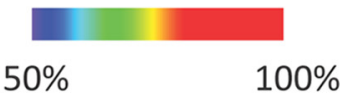

Figure 2. Differential connectivity of the VWFA and FFA (Experiment 1). $\boldsymbol{A}$, Fibers were tracked starting from three ROIs defined by group-level activations during reading, during face perception, and their intersection. For tracking, those group-level ROls were transformed into individual ROls of superficial WM as shown in Figure 1. $\boldsymbol{B}$, Connectivity index to the VWFA and to the FFA, with a threshold of 50\%. C, Value of the $t$ test comparing connectivity from the VWFA minus the FFA and intersection ROIs, and from the FFA minus the VWFA and the intersection ROls, with a threshold of $p<0.05$ FWE corrected. The VWFA was more connected to lateral language-related areas, whereas the FFA was more connected to inferior and mesial temporal areas. The white line delineates the region connected to the VWFA with an index $>50 \%$, as shown in $\boldsymbol{B}$. $\boldsymbol{D}$, Regions of shared connectivity with the VWFA and the FFA. Color coding represents the average of the connectivity index to the VWFA and the FFA, with a 50\% threshold each, restricted to regions without statistical difference between VWFA and FFA. 
Table 1. Coordinates of the seven ventral ROIs (Experiment 2)

\begin{tabular}{llll}
\hline & \multicolumn{2}{l}{ MNI coordinates } & \\
\cline { 2 - 4 } ROI no. & $x$ & $y$ & $z$ \\
\hline 7 & -40 & -43 & -22 \\
6 & -44 & -51 & -21 \\
5 & -45 & -58 & -19 \\
4 & -44 & -66 & -18 \\
3 & -43 & -75 & -16 \\
2 & -40 & -83 & -13 \\
1 & -29 & -91 & -12 \\
\hline
\end{tabular}

MNI coordinates of the center of mass of the seven group-level ROIs into which the VWF system was divided (Experiment 2). The usual coordinates of the main activation peak of the VWFA falls within ROI 5 (MNI $-42,-57$, -15 ; Cohen et al., 2002).

thought to reflect an underlying neural hierarchy, which subtends the perception of complex visual objects, including written words (Riesenhuber and Poggio, 1999; Serre et al., 2007).

In this context, our hypothesis predicts that different posterior-to-anterior regions of the VWF system should exhibit different patterns of anatomical connectivity. First, only the anterior half of the left occipitotemporal sulcus, where the peak of the VWFA is located, should show direct connections to perisylvian language-related cortex; we do not expect more posterior occipital regions to project directly to language areas, but only through the VWFA. Second, the posterior sector, thought to encode single letters or graphemes, should project preferentially to temporal lobe areas and inferior parietal areas involved in grapheme-phoneme conversion; whereas the anterior section, thought to encode larger combinations of letters, should project to anterior temporal areas involved in lexical access and semantic retrieval (Mechelli et al., 2005; Grainger and Ziegler, 2011).

To test those predictions, we compared in a second study the projections of a series of posterior-to-anterior segments of the VWF system. We segmented the VWF system into seven ROIs, which then served as seeds for tracking white matter fibers.

Definition of ROIs

The volume of reading-related activations defined in Materials and Methods was segmented along the anteroposterior axis into seven 8 -mm-thick ROIs spanning the ventral stream from $y=$ -94 to $y=-39$ (Fig. 1; Table 1). This anatomical segmentation was based upon previous segmentation of the VWF system according to its graded functional properties along this axis (Dehaene et al., 2005; Vinckier et al., 2007; Szwed et al., 2011). Note that the union of the five most anterior ROIs was identical to the VWFA ROI used in Experiment 1. We did not use directly those 3D ROIs as seeds, but used the same method as in Experiment 1 to obtain seven individual ROIs restricted to the superficial WM, to which we applied the tracking techniques described in Materials and Methods.

\section{Experiment 2 results}

Figure $3 A$ shows the connectivity of the VWF system averaged across all ROIs. Left-hemispheric projections extended throughout the ventral half of the left hemisphere's surface, as already shown in Experiment 1. This analysis may however miss regions with an average connectivity index lower than $50 \%$, but only receiving projections $>50 \%$ from a subset of regions. Figure $3 B$ thus shows the maximal connectivity index across all seven ROIs, also with a threshold of $50 \%$, yielding a broader and more accurate delineation of the overall connected area.

When visually inspecting the projections of each ROI separately, we found approximately similar patterns, with some regional modulations. Note particularly that only the most posterior ROI 1 had suprathreshold connections with the left calcarine fissure, and with the contralateral mesial occipital cortex through the splenium of the corpus callosum (Fig. 3C). As our aim was to understand the differential connectivity of the successive segments of the VWFA, we performed a pseudo-ANOVA comparing, for each voxel across the whole brain, its connectivity to the seven ROIs. We used the same technique as in Experiment 1 , entering individual normalized smoothed connectivity maps in ANOVAs with one within-subject factor (the 7 ROIs), one regressor of noninterest (the individual volume of the ROI), and subjects treated as a random factor. Figure $3 D$ shows the resulting map of (pseudo-) F values, with a threshold of $F>1.62(p<0.05$; FWE corrected for multiple comparisons). Areas showing differential connectivity overlapped with the connected areas described before, with a slightly more dorsal extension.

To explore the differences in connectivity across the seven ROIs, we performed three additional analyses. First, we simply labeled each voxel, within the overall connected volume as represented in Figure $3 B$, according to the ROI with the most reproducible connectivity with this voxel across subjects (Fig. 4, left). The resulting maps of maximum projection showed markedly different patterns across ROIs: ROI 1 was the seed with maximal projection to the occipital pole, the orbitofrontal cortex (OFC) and the superior temporal pole; ROIs 2 and 3 were the maximum seed for smaller occipitotemporal areas close to the ROIs. For ROI 4, this area extended as an oblique band through the lateral occipitotemporal cortex. For ROIs 5 and 6, projections extended to the mid and superior temporal gyri and to the ventral part of Broca's area. For ROI 7, maximal projections additionally reached the inferior part of the temporal pole.

Second, as this maximum approach lacked statistical quality, we computed the contrasts of each ROI minus the six others, using the same model and threshold as for the $F$ test. Figure 4 (middle and right columns) shows regions with greater connectivity to a given ROI as compared with the other six. The topography was congruent with the topography of the analysis of maximal projections, with some differences: similar to ROI 1, ROI 2 projected to the orbitofrontal and superior temporal pole; and similar to ROI 7, ROI 6 projected to the inferior temporal pole.

Third, to appreciate not only the main sources of projections, but also the full profiles of connectivity, we studied target regions, consisting in 5-mm-radius spheres sampling the overall connected area (Fig. 5A). Spheres were placed in the superficial white matter, within the boundaries of the overall connected area (Fig. $3 B$ ), guided by maxima of the $F$ test across the seven ventral ROIs. We also placed a sphere at MNI $-48,-60,-16$, the coordinates of the so-called LIMA (lateral inferotemporal multimodal area; Cohen et al., 2004), an area responsive to both spoken and written words. For each subject and each target ROI, we computed the mean value of connectivity within the target ROI. Histograms show the average across subjects of this individual connectivity index, for each target and for each ventral ROI. We applied exactly the same method to study the overall contribution of each of the four main involved fasciculi in the connection of the VWF system (Fig. 5B). To this end we used as ROIs the masks created by Thiebaut de Schotten et al. (2011) for the ILF, IFOF, and long and posterior segments of the AF, with a threshold of $50 \%$ of subjects.

Histograms of connectivity profiles naturally agree with the patterns of predominant connections revealed in the two previous analyses. Moreover, one may approximately distinguish three sets of profiles among target regions. First, the orbitofrontal 


\section{A Average connectivity with the ventral ROIs}
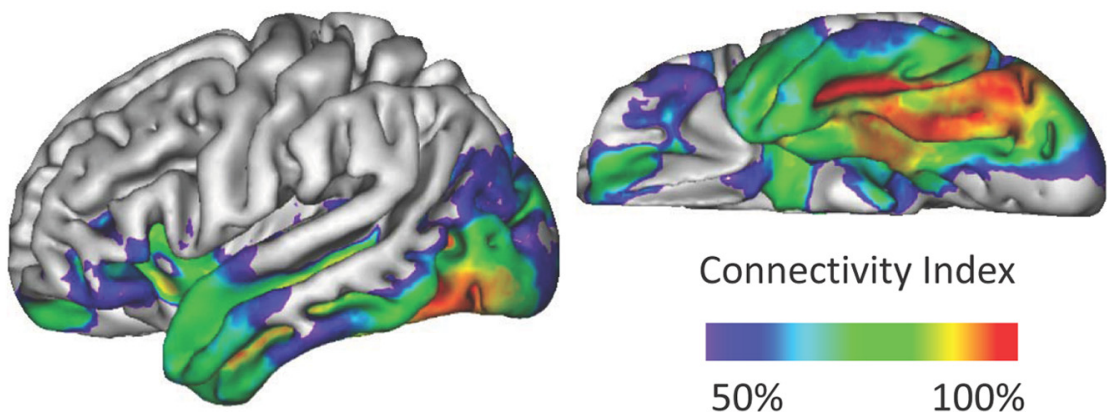

Connectivity Index

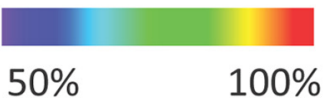

B

Maximum connectivity with ventral ROls: overall connected area
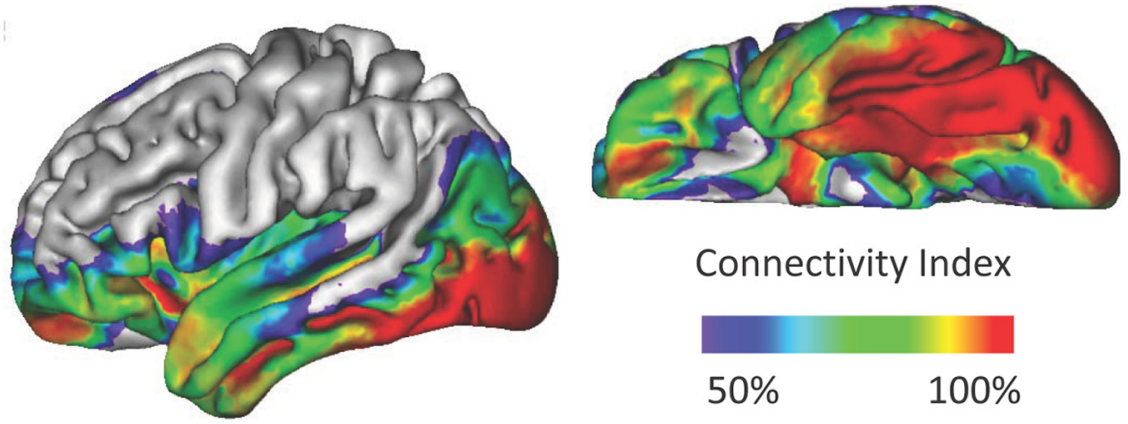

Connectivity Index

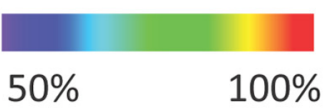

C Callosal connections of ROI 1 with the right hemisphere

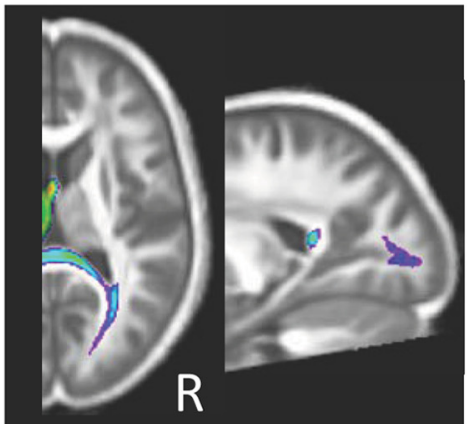

Connectivity Index

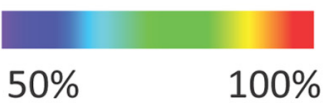

D Differential connectivity with ventral ROIs:

$$
\text { F-test }(P<0.05)
$$

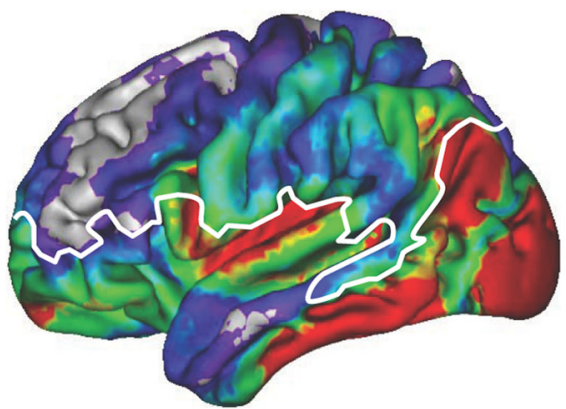

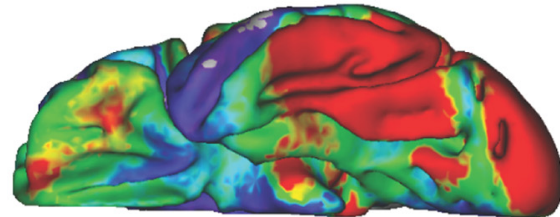

F value

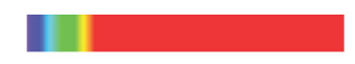

$2.72 \quad 33$

Figure 3. Overall connectivity of the VWF system (Experiment 2). A, Average connectivity index to the seven ROls, with a threshold of $50 \%$. B, Maximum connectivity index across the seven ROls, with a threshold of $50 \%$. C, Connections from the most posterior R01 1 to the right-hemispheric occipital lobe through the anterior part of the splenium, with a threshold of $50 \%$ in the connectivity index. $\boldsymbol{D}$. Value of the F test comparing connectivity from the seven ROIs (threshold of $p<0.05 \mathrm{FWE}$ corrected). In summary, a large ventral expanse of the brain receives connections from the VWF system, always with a differential contribution of the seven ROls. The white line delineates the region connected to at least one ROl with a connectivity index $>50 \%$, as shown in $\boldsymbol{B}$. 


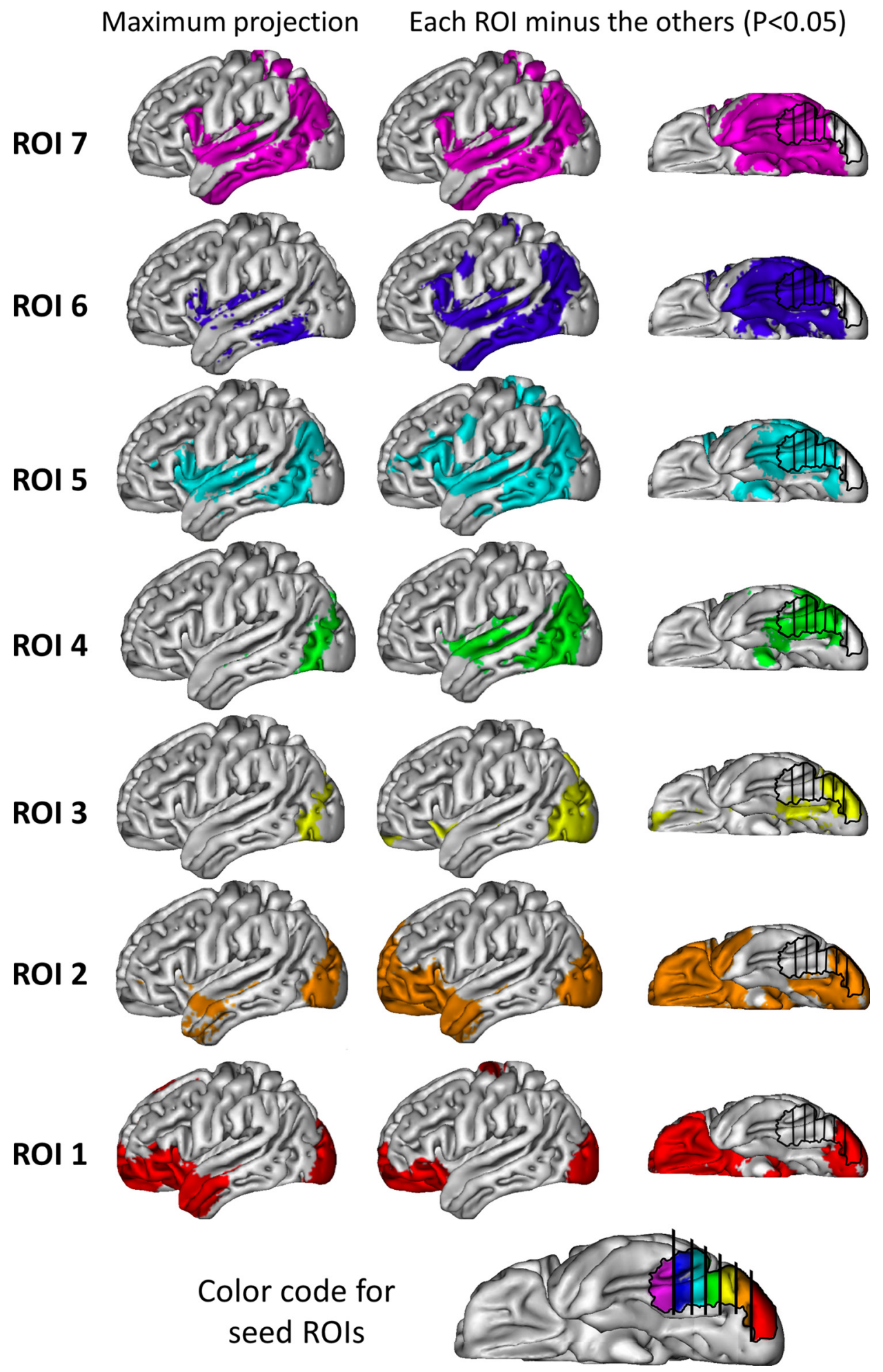

Figure 4. Differential connectivity of ventral ROIs spanning the length of the VWFA (Experiment 2). The seven ROls showed different patterns of connection with distant regions, as illustrated by maps of maximum projections (left column), and by statistical maps contrasting each ROI minus the other six (middle and right columns; threshold of $p<0.05$ FWE corrected). A reminder of the color code for the seven ROls is presented at the bottom. The most posterior ROIs had connections with the orbitofrontal and polar temporal regions, intermediate ROls had connections with perisylvian language-related regions, and the most anterior ROIs had additional connections with anterior ventral temporal regions.

region, the occipital, and the superior temporal pole were essentially connected to the most posterior ROIs, i.e., ROI 1 and to a lesser degree ROI 2 . Those connections were mostly supported by the IFOF, whose distinctive profile shows it to be mostly connected to ROIs 1 and 2. Second, ROIs in perisylvian language- related regions [ventral Broca's area and superior temporal gyrus (STG)] show another distinctive profile, with a selective and comparable connectivity to the three most anterior ROIs 5,6 , and 7. Those connections were supported by the long segment of the $\mathrm{AF}$ and the ILF, respectively. The posterior middle temporal 


\section{Connectivity profiles of the ventral ROIs}

A

\section{with distant targets}

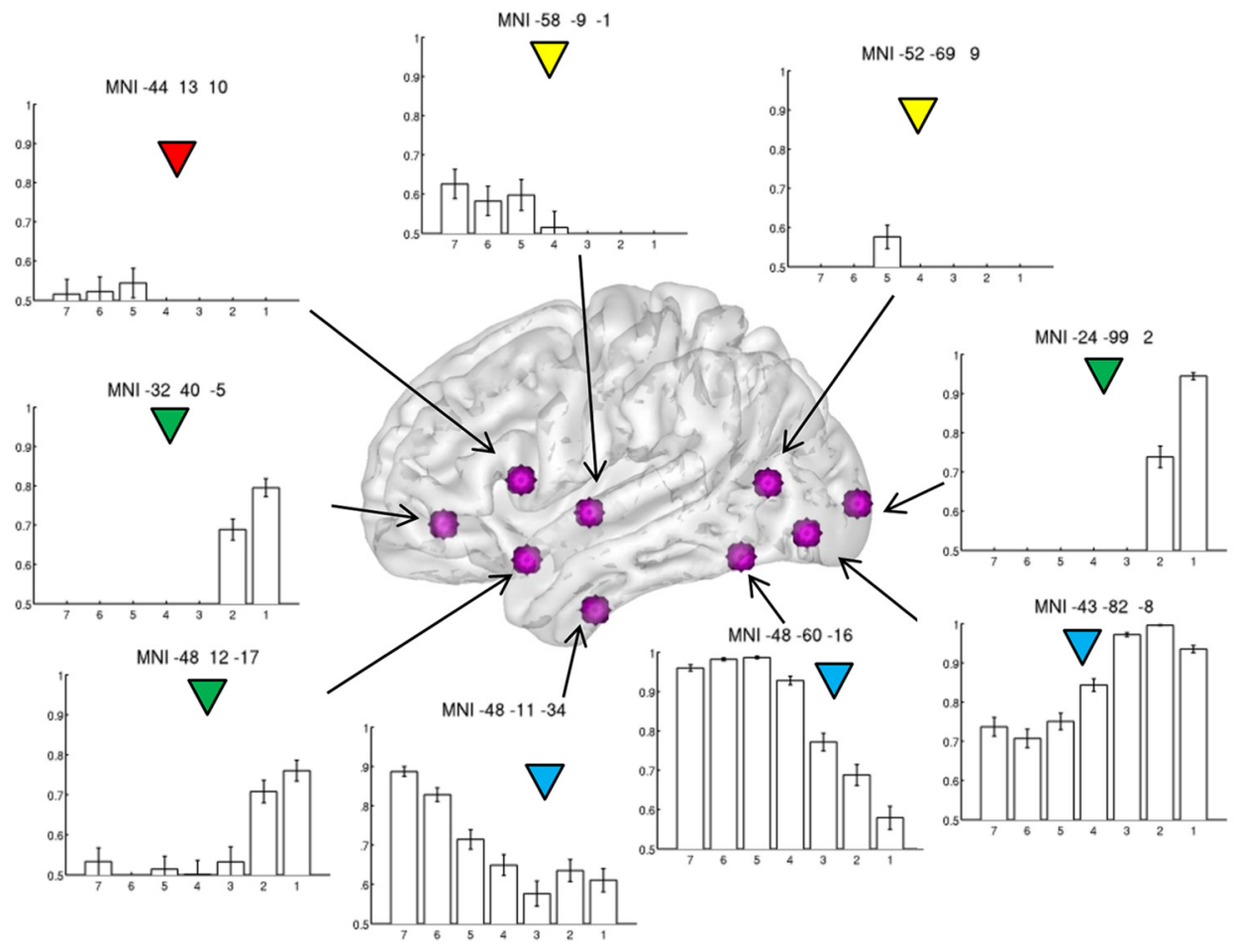

B

with major fiber tracts
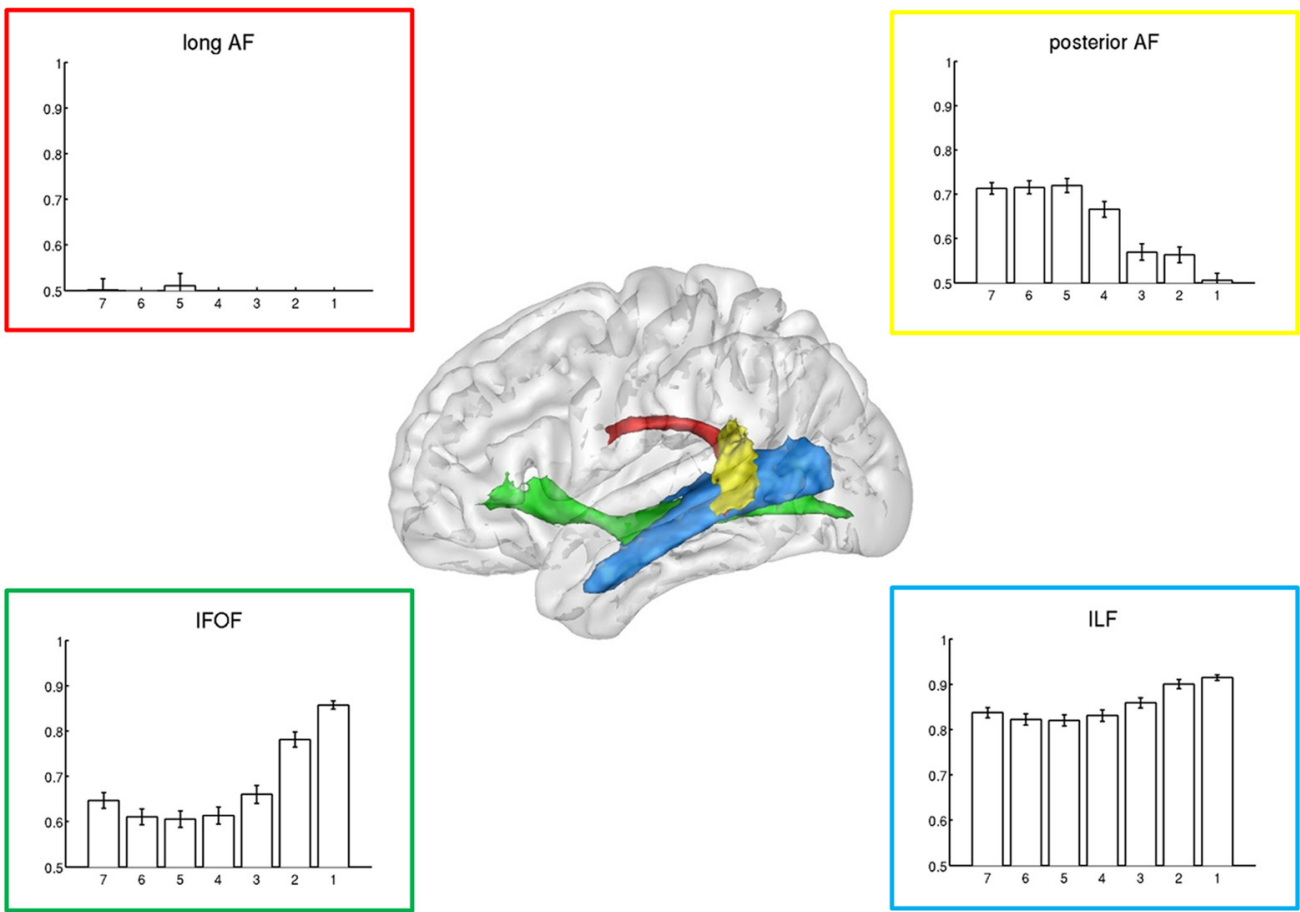

Figure 5. Connectivity profiles of the seven ventral ROls. $A$, Profiles of connectivity between the seven ventral ROIs and distant targets. $B$, Profiles of connectivity between the seven ventral ROIs and the main relevant fiber tracts (IFOF, green; posterior segment of the AF, yellow; long segment of the AF, red; ILF, blue), from Thiebaut de Schotten et al. (2011). Bars represent the connectivity indices to each of the seven ventral ROls, averaged over the target's volume and across subjects. Error bars represent \pm 1 SEM after subtraction of each subject's overall mean. The color of triangles in $\boldsymbol{A}$ refers to the fiber tract in $\boldsymbol{B}$ predominantly connecting each target. In summary, the IFOF links the most posterior ROIs with anterior frontotemporal regions, the AF, especially its posterior vertical limb, links more anterior ROIs to perisylvian language areas, and the ILF establishes links within the whole extent of the inferotemporal region. 
gyrus (MTG) is an interesting variant of this pattern with a predominant connection through the posterior segment of the AF to ROI 5 (which is the maximum source of projection to this area), whereas ROIs 6 and 7 were slightly below the 50\% threshold. Third, the three ventral spheres showed profiles suggestive of the ILF, as this ventral fasciculus is heavily connected to all ROIs, presumably trafficking information all along the ventral temporal cortex. The most anterior ventral temporal region is of particular interest, as it is the only one to be more connected to the most anterior ROI 7 even compared to the neighboring ROIs 6 and 5.

\section{Experiment 2 summary}

We showed that segments of the VWF system arrayed along the anteroposterior axis have significantly different patterns of connection, involving to various degrees perisylvian language areas, orbitofrontal and anterior temporal regions, and early visual cortex. The functional significance of those connections will be discussed below.

\section{Discussion}

Two predictions prompted the present work. First, we predicted that the VWFA and the immediately neighboring FFA should preferentially project to networks related to language and to social/emotional cognition, respectively. Second, we predicted that segments of the VWF system supporting different orthographic representations should be differentially connected to the components of the reading network.

\section{VWFA versus FFA: specificity of the connection pattern}

We found a set of mesial occipitotemporal regions connected to the FFA more than to the VWFA (Fig. 2C), fitting with a metaanalysis of $>100$ studies of activations during face processing (Fusar-Poli et al., 2009). Conversely, the VWFA was more connected to perisylvian language areas.

The OFC was equally connected to the VWFA and the FFA. Its predominant links with the most posterior ROIs fit with the idea that it plays a noncategory-specific top-down role in visual perception (Bar et al., 2006). This influence could be triggered by the early projection of low-frequency shape information, supported by the magnocellular system, allowing for subsequent predictive feedback (Kveraga et al., 2007; Chaumon et al.,2013).

At a deeper causal level, it has been proposed that "domainspecificity emerges (...) because of innate connectivity with a network of regions that also process information about that domain" (Mahon and Caramazza, 2011). The difference in connectivity between the VWFA and the FFA may explain why those two regions were selected during development to specialize for words and faces. Accordingly, Saygin et al. (2011) showed that individual anatomical connectivity predicts the location of activations to faces. This hypothesis is not exclusive of the role of a priori perceptual biases. An intersection of constraints may make the VWFA site most appropriate for orthographic decoding, and may in turn, have constrained the form that scripts take across cultures (Changizi and Shimojo, 2005; Changizi, 2006; Dehaene, 2009). Still, the fact that reading-related ventral activations have the same topography in blind and sighted subjects suggests that connections with language may be sufficient to determine the reproducible location of the VWFA (Reich et al., 2011; StriemAmit et al., 2012).

\section{Functional subdivision and connectivity of the VWF system} The canonical peak of the VWFA falls within current ROI 5 (Cohen et al., 2002). However, reading activates a whole strip of occipitotemporal cortex, and more refined contrasts have revealed functional differences along the rostrocaudal axis, which we predicted, should be associated to distinct connectivity patterns. Schematically, in line with the local combination detector model (Dehaene et al., 2005), ROIs 1 and 2 fulfill nonspecific perceptual functions for encoding letters shapes, ROIs 3 and 4 compute invariant representations of letters (Dehaene et al., 2001, 2004; Devlin et al., 2004; Qiao et al., 2010), and the VWF system anterior to $\sim y=-60$ (ROIs 5-7) identify higher-level orthographic components (Vinckier et al., 2007; Glezer et al., 2009; Szwed et al., 2011). This pattern fits neatly with the functional fractionation of the VWF system observed by Danelli et al. (2013). Privileged communication between the anterior VWF system and language areas is further supported by studies using functional correlations between the VWFA and distant areas (Bokde et al., 2001; Bitan et al., 2005; Mechelli et al., 2005; Yoncheva et al., 2010; Koyama et al., 2011).

In this context, we may propose the following interpretation of the results of Experiment 2.

(1) The VWF system projects to a large expanse of the ventral and inferior lateral aspects of the brain. This includes the areas shown by Yeatman et al. (2013) to be connected to the VWFA, plus lateral and superior temporal, and inferior frontal regions. Those additional projections were mostly linked to ROIs 5-7, which are on average anterior to the seed used by Yeatman et al. (2013). This may explain why Yeatman et al. (2013) did not identify the arcuate fasciculus as linking the VWFA to perisylvian regions. They rather emphasized the VOF, a fascicle of vertical fibers which lies posterior to the arcuate fasciculus (Dejerine, 1895).

(2) Visual input mainly enters through ROIs 1 and 2. ROI 2 is connected to the left occipital pole, whereas ROI 1 also receives connections from the left calcarine region and from the contralateral occipital lobe. Callosal pathways cross thick bundles of fibers (Abe et al., 2004; Hofer and Frahm, 2006) and we may have missed connections to more anterior segments of the VWF system (Molko et al., 2002; Clarke, 2003).

(3) ROIs 1 and 2 have connections to orbitofrontal regions through the IFOF, which might be implicated in the early activation of the OFC during visual perception, and its role in the top-down facilitation of visual recognition (Bar et al., 2006; Matsumoto and Kakigi, 2014).

(4) ROIs 2 and 3 show connections mostly to the neighboring cortex, presumably bridging the gap between low-level visual analysis and invariant letters representations.

(5) ROIs 5-7 are connected to language areas, whereas ROI 4 shows a transitional pattern between ROIs 3 and 5. Still, the precise patterns of connection of ROIs 5-7 differ in interesting ways:

First, the posterior MTG receives strong projections from ROI 5. The posterior MTG region is activated during reading (Jobard et al., 2003), underactivated in dyslexic readers (Richlan et al., 2009), and activated in proportion to grapheme-to-phoneme mapping difficulty (Graves et al., 2010). Considering the positive correlation of fMRI activation in ROI 5 with bigram frequency (Binder et al., 2006), one may suggest that ROI 5 and the posterior MTG constitute an anatomically connected tandem involved in grapheme-to-phoneme mapping. 
Second, the anterior basal temporal lobe receives strong projections from ROI 7. It has been proposed that this region plays the role of an amodal hub binding information across modalities and domains, contributing to concept representation (Damasio, 1989; Martin and Chao, 2001; Patterson et al., 2007; Binder and Desai, 2011). As such, it would be part of the "deep" reading route (Wilson et al., 2009; Mion et al., 2010). This supramodal feature starts anterior to the VWF system as defined here (Giraud and Price, 2001; Cattinelli et al., 2013; Taylor et al., 2013). A meta-analysis of semantic activation studies shows a fusiform/parahippocampal focus $\sim y=35$ (Binder et al., 2009). Accordingly, in semantic dementia patients, a fusiform ROI anterior to $y=-31$ shows negative correlation between semantic memory tests and glucose metabolism (Mion et al., 2010). Assuming that the most anterior sectors of the VWF system detect complex multiletter clusters (Dehaene et al., 2005), it makes good sense that they should provide the main orthographic input to neighboring semantic regions.

Third, Broca's area and the STG are equally connected to ROIs 5-7. van Atteveldt et al. (2004) showed that the STG mediates the influence of script on speech perception (van Atteveldt et al., 2009; Blomert, 2011). They argued that such influence is probably relayed through multimodal convergence zones, but also suggested that direct visualto-auditory connections might be involved (Falchier et al., 2010). A parallel may be drawn between our results and the demonstration of direct anatomical connections, within the right hemisphere, between the FFA and superior temporal areas devoted to voice recognition (Blank et al., 2011). This network devoted to the recognition of individuals may be the counterpart of the left-hemispheric system subtending the visual and auditory recognition of words (Cohen et al., 2004). Regarding Broca's area, we found connections involving the ventral opercular part, which is thought to be involved in phonological processing (Jobard et al., 2003; Binder et al., 2009; Price, 2012).

(6) Finally, all seven ROIs were connected with each other. Such local connections transiting through the U-shape fibers of the ILF, represent the intrinsic connectivity of the ventral pathway (Kravitz et al., 2013), and may subtend the formation of representations of increasing complexity and invariance (Dehaene et al., 2005; Serre et al., 2007; DiCarlo et al., 2012; Rolls, 2012).

One may note that connections to the angular gyrus may appear relatively sparse and restricted to the very posterior part of the inferior parietal lobule, despite the traditional role attributed to the angular gyrus in reading (Dejerine, 1892; Geschwind, 1965). Actually, angular activations during reading seem restricted to semantically oriented tasks (Price, 2012; Taylor et al., 2013), in agreement with a supramodal function of integration and semantic access (Binder et al., 2009).

\section{Conclusion}

The present results clarify the anatomical connections of the VWFA. They reveal a pattern of connectivity to language areas at the precise left occipitotemporal location, which in readers of all cultures, is preferentially activated by written words. Those results confirm that the VWFA plays a prominent role in reading by serving as an interface between the ventral visual recognition system and perisylvian language areas. We propose that connec- tivity to language areas, over and above visual factors, may be the primary determinant of VWFA localization. However, conclusively separating the causes versus the consequences of learning to read would require replication of the present work in prereading children, in a longitudinal context, to directly test whether the location of the developing VWFA can be predicted by a prior pattern of long-distance connectivity.

\section{References}

Abe O, Masutani Y, Aoki S, Yamasue H, Yamada H, Kasai K, Mori H, Hayashi N, Masumoto T, Ohtomo K (2004) Topography of the human corpus callosum using diffusion tensor tractography. J Comput Assist Tomogr 28:533-539. CrossRef Medline

Avants BB, Epstein CL, Grossman M, Gee JC (2008) Symmetric diffeomorphic image registration with cross-correlation: evaluating automated labeling of elderly and neurodegenerative brain. Med Image Anal 12:26-41. CrossRef Medline

Bar M, Kassam KS, Ghuman AS, Boshyan J, Schmid AM, Dale AM, Hämäläinen MS, Marinkovic K, Schacter DL, Rosen BR, Halgren E (2006) Topdown facilitation of visual recognition. Proc Natl Acad Sci U S A 103: 449-454. CrossRef Medline

Binder JR, Desai RH (2011) The neurobiology of semantic memory. Trends Cogn Sci 15:527-536. CrossRef Medline

Binder JR, Medler DA, Westbury CF, Liebenthal E, Buchanan L (2006) Tuning of the human left fusiform gyrus to sublexical orthographic structure. Neuroimage 33:739-748. CrossRef Medline

Binder JR, Desai RH, Graves WW, Conant LL (2009) Where is the semantic system? A critical review and meta-analysis of 120 functional neuroimaging studies. Cereb Cortex 19:2767-2796. CrossRef Medline

Bitan T, Booth JR, Choy J, Burman DD, Gitelman DR, Mesulam MM (2005) Shifts of effective connectivity within a language network during rhyming and spelling. J Neurosci 25:5397-5403. CrossRef Medline

Blank H, Anwander A, von Kriegstein K (2011) Direct structural connections between voice- and face-recognition areas. J Neurosci 31:1290612915. CrossRef Medline

Blomert L (2011) The neural signature of orthographic-phonological binding in successful and failing reading development. Neuroimage 57:695703. CrossRef Medline

Bokde AL, Tagamets MA, Friedman RB, Horwitz B (2001) Functional interactions of the inferior frontal cortex during the processing of words and word-like stimuli. Neuron 30:609-617. CrossRef Medline

Bolger DJ, Perfetti CA, Schneider W (2005) Cross-cultural effect on the brain revisited: universal structures plus writing system variation. Hum Brain Mapp 25:92-104. CrossRef Medline

Cai Q, Lavidor M, Brysbaert M, Paulignan Y, Nazir TA (2008) Cerebral lateralization of frontal lobe language processes and lateralization of the posterior visual word processing system. J Cogn Neurosci 20:672-681. CrossRef Medline

Cai Q, Paulignan Y, Brysbaert M, Ibarrola D, Nazir TA (2010) The left ventral occipito-temporal response to words depends on language lateralization but not on visual familiarity. Cereb Cortex 20:1153-1163. CrossRef Medline

Catani M, Jones DK, ffytche DH (2005) Perisylvian language networks of the human brain. Ann Neurol 57:8-16. CrossRef Medline

Cattinelli I, Borghese NA, Gallucci M, Paulesu E (2013) Reading the reading brain: a new meta-analysis of functional imaging data on reading. J Neurolinguistics 26:214-238. CrossRef

Changizi MA (2006) The optimal human ventral stream from estimates of the complexity of visual objects. Biol Cybern 94:415-426. CrossRef Medline

Changizi MA, Shimojo S (2005) Character complexity and redundancy in writing systems over human history. Proc Biol Sci 272:267-275. CrossRef Medline

Chaumon M, Kveraga K, Barrett LF, Bar M (2013) Visual predictions in the orbitofrontal cortex rely on associative content. Cereb Cortex 24:2899_ 2907. CrossRef Medline

Clarke S (2003) The role of homotopic and heterotopic callosal connections in humans. In: The parallel brain (Zaidel E, Iacoboni M, eds), pp 461472. Cambridge: MIT.

Cohen L, Dehaene S, Naccache L, Lehéricy S, Dehaene-Lambertz G, Hénaff MA, Michel F (2000) The visual word form area: spatial and temporal 
characterization of an initial stage of reading in normal subjects and posterior split-brain patients. Brain 123:291-307. CrossRef Medline

Cohen L, Lehéricy S, Chochon F, Lemer C, Rivaud S, Dehaene S (2002) Language-specific tuning of visual cortex? Functional properties of the visual word form area. Brain 125:1054-1069. CrossRef Medline

Cohen L, Martinaud O, Lemer C, Lehéricy S, Samson Y, Obadia M, Slachevsky A, Dehaene S (2003) Visual word recognition in the left and right hemispheres: anatomical and functional correlates of peripheral alexias. Cereb Cortex 13:1313-1333. CrossRef Medline

Cohen L, Jobert A, Le Bihan D, Dehaene S (2004) Distinct unimodal and multimodal regions for word processing in the left temporal cortex. Neuroimage 23:1256-1270. CrossRef Medline

Damasio AR (1989) Time-locked multiregional retroactivation: a systemslevel proposal for the neural substrates of recall and recognition. Cognition 33:25-62. CrossRef Medline

Danelli L, Berlingeri M, Bottini G, Ferri F, Vacchi L, Sberna M, Paulesu E (2013) Neural intersections of the phonological, visual magnocellular and motor/cerebellar systems in normal readers: implications for imaging studies on dyslexia. Hum Brain Mapp 34:2669-2687. CrossRef Medline

Dehaene S (2009) Reading in the brain. New York: Penguin Viking.

Dehaene S, Cohen L (2011) The unique role of the visual word form area in reading. Trends Cogn Sci 15:254-262. CrossRef Medline

Dehaene S, Naccache L, Cohen L, Bihan DL, Mangin JF, Poline JB, Rivière D (2001) Cerebral mechanisms of word masking and unconscious repetition priming. Nat Neurosci 4:752-758. CrossRef Medline

Dehaene S, Le Clec'H G, Poline JB, Le Bihan D, Cohen L (2002) The visual word form area: a prelexical representation of visual words in the fusiform gyrus. Neuroreport 13:321-325. CrossRef Medline

Dehaene S, Jobert A, Naccache L, Ciuciu P, Poline JB, Le Bihan D, Cohen L (2004) Letter binding and invariant recognition of masked words: behavioral and neuroimaging evidence. Psychol Sci 15:307-313. CrossRef Medline

Dehaene S, Cohen L, Sigman M, Vinckier F (2005) The neural code for written words: a proposal. Trends Cogn Sci 9:335-341. CrossRef Medline

Dejerine J (1892) Contribution à l'étude anatomo-pathologique et clinique des différentes variétés de cécité verbale. Mem Soc Biol 4:61-90.

Dejerine J (1895) Anatomie des centres nerveux. Paris: Rueff et Cie.

Descoteaux M, Angelino E, Fitzgibbons S, Deriche R (2007) Regularized, fast, and robust analytical Q-ball imaging. Magn Reson Med 58:497-510. CrossRef Medline

Devlin JT, Jamison HL, Matthews PM, Gonnerman LM (2004) Morphology and the internal structure of words. Proc Natl Acad Sci U S A 101:1498414988. CrossRef Medline

DiCarlo JJ, Zoccolan D, Rust NC (2012) How does the brain solve visual object recognition? Neuron 73:415-434. CrossRef Medline

Dubois J, Poupon C, Lethimonnier F, Le Bihan D (2006) Optimized diffusion gradient orientation schemes for corrupted clinical DTI data sets. MAGMA 19:134-143. CrossRef Medline

Epelbaum S, Pinel P, Gaillard R, Delmaire C, Perrin M, Dupont S, Dehaene S, Cohen L (2008) Pure alexia as a disconnection syndrome: new diffusion imaging evidence for an old concept. Cortex 44:962-974. CrossRef Medline

Falchier A, Schroeder CE, Hackett TA, Lakatos P, Nascimento-Silva S, Ulbert I, Karmos G, Smiley JF (2010) Projection from visual areas V2 and prostriata to caudal auditory cortex in the monkey. Cereb Cortex 20:15291538. CrossRef Medline

Fusar-Poli P, Placentino A, Carletti F, Landi P, Allen P, Surguladze S, Benedetti F, Abbamonte M, Gasparotti R, Barale F, Perez J, McGuire P, Politi P (2009) Functional atlas of emotional faces processing: a voxel-based meta-analysis of 105 functional magnetic resonance imaging studies. J Psychiatry Neurosci 34:418-432. Medline

Geschwind N (1965) Disconnexion syndromes in animals and man: II. Brain 88:585-585. Medline

Giraud AL, Price CJ (2001) The constraints functional neuroanatomy places on classical models of auditory word processing. J Cogn Neurosci 13:754-765. CrossRef Medline

Glezer LS, Riesenhuber M (2013) Individual variability in location impacts orthographic selectivity in the "visual word form area." J Neurosci 33: 11221-11226. CrossRef Medline

Glezer LS, Jiang X, Riesenhuber M (2009) Evidence for highly selective neuronal tuning to whole words in the "visual word form area." Neuron 62:199-204. CrossRef Medline
Grainger J, Ziegler JC (2011) A dual-route approach to orthographic processing. Front Psychol 2:54. CrossRef Medline

Graves WW, Desai R, Humphries C, Seidenberg MS, Binder JR (2010) Neural systems for reading aloud: a multiparametric approach. Cereb Cortex 20:1799-1815. CrossRef Medline

Hasson U, Levy I, Behrmann M, Hendler T, Malach R (2002) Eccentricity bias as an organizing principle for human high-order object areas. Neuron 34:479-490. CrossRef Medline

Hofer S, Frahm J (2006) Topography of the human corpus callosum revisited: comprehensive fiber tractography using diffusion tensor magnetic resonance imaging. Neuroimage 32:989-994. CrossRef Medline

Jobard G, Crivello F, Tzourio-Mazoyer N (2003) Evaluation of the dual route theory of reading: a metanalysis of 35 neuroimaging studies. Neuroimage 20:693-712. CrossRef Medline

Klein A, Andersson J, Ardekani BA, Ashburner J, Avants B, Chiang MC, Christensen GE, Collins DL, Gee J, Hellier P, Song JH, Jenkinson M, Lepage C, Rueckert D, Thompson P, Vercauteren T, Woods RP, Mann JJ, Parsey RV (2009) Evaluation of 14 nonlinear deformation algorithms applied to human brain MRI registration. Neuroimage 46:786-802. CrossRef Medline

Koyama MS, Di Martino A, Zuo XN, Kelly C, Mennes M, Jutagir DR, Castellanos FX, Milham MP (2011) Resting-state functional connectivity indexes reading competence in children and adults. J Neurosci 31:86178624. CrossRef Medline

Kravitz DJ, Saleem KS, Baker CI, Ungerleider LG, Mishkin M (2013) The ventral visual pathway: an expanded neural framework for the processing of object quality. Trends Cogn Sci 17:26-49. CrossRef Medline

Kveraga K, Boshyan J, Bar M (2007) Magnocellular projections as the trigger of top-down facilitation in recognition. J Neurosci 27:13232-13240. CrossRef Medline

Lerner Y, Hendler T, Ben-Bashat D, Harel M, Malach R (2001) A hierarchical axis of object processing stages in the human visual cortex. Cereb Cortex 11:287-297. CrossRef Medline

Lundqvist D, Flykt A, Öhman A (1998) The Karolinska directed emotional faces: KDEF. In: CD ROM from Department of Clinical Neuroscience, Psychology section, Karolinska Institutet.

Mahon BZ, Caramazza A (2011) What drives the organization of object knowledge in the brain? Trends Cogn Sci 15:97-103. CrossRef Medline

Martin A, Chao LL (2001) Semantic memory and the brain: structure and processes. Curr Opin Neurobiol 11:194-201. CrossRef Medline

Matsumoto A, Kakigi R (2014) Subliminal semantic priming changes the dynamic causal influence between the left frontal and temporal cortex. J Cogn Neurosci 26:165-174. CrossRef Medline

Mechelli A, Crinion JT, Long S, Friston KJ, Lambon Ralph MA, Patterson K, McClelland JL, Price CJ (2005) Dissociating reading processes on the basis of neuronal interactions. J Cogn Neurosci 17:1753-1765. CrossRef Medline

Mion M, Patterson K, Acosta-Cabronero J, Pengas G, Izquierdo-Garcia D, Hong YT, Fryer TD, Williams GB, Hodges JR, Nestor PJ (2010) What the left and right anterior fusiform gyri tell us about semantic memory. Brain 133:3256-3268. CrossRef Medline

Molko N, Cohen L, Mangin JF, Chochon F, Lehéricy S, Le Bihan D, Dehaene S (2002) Visualizing the neural bases of a disconnection syndrome with diffusion tensor imaging. J Cogn Neurosci 14:629-636. CrossRef Medline

Nichols TE, Holmes AP (2002) Nonparametric permutation tests for functional neuroimaging: a primer with examples. Hum Brain Mapp 15:1-25. CrossRef Medline

Nobre AC, Allison T, McCarthy G (1994) Word recognition in the human inferior temporal lobe. Nature 372:260-263. CrossRef Medline

Oldfield RC (1971) The assessment and analysis of handedness: the Edinburgh inventory. Neuropsychologia 9:97-113. CrossRef Medline

Patterson K, Nestor PJ, Rogers TT (2007) Where do you know what you know? The representation of semantic knowledge in the human brain. Nat Rev Neurosci 8:976-987. CrossRef Medline

Perrin M, Poupon C, Cointepas Y, Rieul B, Golestani N, Pallier C, Rivière D, Constantinesco A, Le Bihan D, Mangin JF (2005) Fiber tracking in $\mathrm{q}$-ball fields using regularized particle trajectories. Inf Process Med Imaging 19:52-63. Medline

Pflugshaupt T, Gutbrod K, Wurtz P, von Wartburg R, Nyffeler T, de Haan B, Karnath HO, Mueri RM (2009) About the role of visual field defects in pure alexia. Brain 132:1907-1917. CrossRef Medline 
Pinel P, Dehaene S (2010) Beyond hemispheric dominance: brain regions underlying the joint lateralization of language and arithmetic to the left hemisphere. J Cogn Neurosci 22:48-66. CrossRef Medline

Pinel P, Thirion B, Meriaux S, Jobert A, Serres J, Le Bihan D, Poline JB, Dehaene S (2007) Fast reproducible identification and large-scale databasing of individual functional cognitive networks. BMC Neurosci 8:91-109. CrossRef Medline

Price CJ (2012) A review and synthesis of the first 20 years of PET and fMRI studies of heard speech, spoken language and reading. Neuroimage 62: 816-847. CrossRef Medline

Qiao E, Vinckier F, Szwed M, Naccache L, Valabrègue R, Dehaene S, Cohen L (2010) Unconsciously deciphering handwriting: subliminal invariance for handwritten words in the visual word form area. Neuroimage 49: 1786-1799. CrossRef Medline

Reese TG, Heid O, Weisskoff RM, Wedeen VJ (2003) Reduction of eddycurrent-induced distortion in diffusion MRI using a twice-refocused spin echo. Magn Reson Med 49:177-182. CrossRef Medline

Reich L, Szwed M, Cohen L, Amedi A (2011) A ventral visual stream reading center independent of visual experience. Curr Biol 21:363-368. CrossRef Medline

Richlan F, Kronbichler M, Wimmer H (2009) Functional abnormalities in the dyslexic brain: a quantitative meta-analysis of neuroimaging studies. Hum Brain Mapp 30:3299-3308. CrossRef Medline

Riesenhuber M, Poggio T (1999) Hierarchical models of object recognition in cortex. Nat Neurosci 2:1019-1025. CrossRef Medline

Rolls ET (2012) Invariant visual object and face recognition: neural and computational bases, and a model, VisNet. Front Comput Neurosci 6:35. CrossRef Medline

Saygin ZM, Osher DE, Koldewyn K, Reynolds G, Gabrieli JD, Saxe RR (2011) Anatomical connectivity patterns predict face selectivity in the fusiform gyrus. Nat Neurosci 15:321-327. CrossRef Medline

Serre T, Oliva A, Poggio T (2007) A feedforward architecture accounts for rapid categorization. Proc Natl Acad Sci U S A 104:6424-6429. CrossRef Medline

Smith SM, Nichols TE (2009) Threshold-free cluster enhancement: addressing problems of smoothing, threshold dependence and localisation in cluster inference. Neuroimage 44:83-98. CrossRef Medline

Striem-Amit E, Cohen L, Dehaene S, Amedi A (2012) Reading with sounds: sensory substitution selectively activates the visual word form area in the blind. Neuron 76:640-652. CrossRef Medline

Szwed M, Dehaene S, Kleinschmidt A, Eger E, Valabrègue R, Amadon A,
Cohen L (2011) Specialization for written words over objects in the visual cortex. Neuroimage 56:330-344. CrossRef Medline

Taylor JS, Rastle K, Davis MH (2013) Can cognitive models explain brain activation during word and pseudoword reading? A meta-analysis of 36 neuroimaging studies. Psychol Bull 139:766-791. CrossRef Medline

Thiebaut de Schotten M, Ffytche DH, Bizzi A, Dell'Acqua F, Allin M, Walshe M, Murray R, Williams SC, Murphy DG, Catani M (2011) Atlasing location, asymmetry and inter-subject variability of white matter tracts in the human brain with MR diffusion tractography. Neuroimage 54:49-59. CrossRef Medline

Thiebaut de Schotten M, Urbanski M, Valabregue R, Bayle DJ, Volle E (2014) Subdivision of the occipital lobes: an anatomical and functional MRI connectivity study. Cortex 56:121-137. CrossRef Medline

van Atteveldt N, Formisano E, Goebel R, Blomert L (2004) Integration of letters and speech sounds in the human brain. Neuron 43:271-282. CrossRef Medline

van Atteveldt N, Roebroeck A, Goebel R (2009) Interaction of speech and script in human auditory cortex: insights from neuro-imaging and effective connectivity. Hear Res 258:152-164. CrossRef Medline

Van der Haegen L, Cai Q, Brysbaert M (2012) Colateralization of Broca's area and the visual word form area in left-handers: fMRI evidence. Brain Lang 122:171-178. CrossRef Medline

Ventura P, Fernandes T, Cohen L, Morais J, Kolinsky R, Dehaene S (2013) Literacy acquisition reduces the influence of automatic holistic processing of faces and houses. Neurosci Lett 554:105-109. CrossRef Medline

Vinckier F, Dehaene S, Jobert A, Dubus JP, Sigman M, Cohen L (2007) Hierarchical coding of letter strings in the ventral stream: dissecting the inner organization of the visual word-form system. Neuron 55:143-156. CrossRef Medline

Wilson SM, Brambati SM, Henry RG, Handwerker DA, Agosta F, Miller BL, Wilkins DP, Ogar JM, Gorno-Tempini ML (2009) The neural basis of surface dyslexia in semantic dementia. Brain 132:71-86. CrossRef Medline

Yeatman JD, Dougherty RF, Ben-Shachar M, Wandell BA (2012) Development of white matter and reading skills. Proc Natl Acad Sci U S A 109: E3045-E3053. CrossRef Medline

Yeatman JD, Rauschecker AM, Wandell BA (2013) Anatomy of the visual word form area: adjacent cortical circuits and long-range white matter connections. Brain Lang 125:146-155. CrossRef Medline

Yoncheva YN, Zevin JD, Maurer U, McCandliss BD (2010) Auditory selective attention to speech modulates activity in the visual word form area. Cereb Cortex 20:622-632. CrossRef Medline 